\title{
Potentiality of DNA Sensors \\ in Activating Immune System \\ in Emerging Viral Infectious Diseases
}

\author{
Siddhesh U. Sapre and Preethika Nair
}

\begin{abstract}
Viruses are obligatory intracellular parasites and hijack the host cell machinery to make more identical copies of it and continue self-propagation. They attach and replicate in the susceptible and permissive hosts and host derived cell lines. They enter the cells either through direct attachment, receptor-mediated endocytosis, or phagocytosis. Hence, to thwart the invasion by viruses, hosts have developed immunity in ascending stages — intrinsic, innate and adaptive immunity. A robust intrinsic and innate immune response governs an effective adaptive immune response, should that be needed. Both enveloped as well as nonenveloped viruses are subject to distinct types of DNA sensors, subject to their site of replication. DNA sensors of viral PAMPs can be classified into three types, based on the location of their PAMPs in the host cellular compartment viz. cell surface, cytoplasmic and nuclear. The host cell membrane both, surface as well as intra cellular, is continuously monitored for the non-host, pathogenic components or PAMPs. Among the intracellular sensors of the viral genome, there are two types - essentially due to the two types of major viral genomes i.e. RNA and DNA sensors. The cytosolic DNA sensors include AIM2, IFI16, cGAS, RNA Pol III, DNA-PK, DDX9, DHX36, DDX41, DDX60, DAI, LRRFIP1, HMGB, ABCF1 and MRE11. PYHIN family of sensors include AIM2, IFI16, IFIX and MNDA. Another recently discovered family of sensor called stimulator of interferon (IFN) genes (STING), specifically houses on the endoplasmic reticulum (ER) and functions in association with its upstream sensor, cGAS. Some DNA sensors shuttle between the cytosol and nucleus pre- and post-extraneous DNA binding. These include IFI16, IFIX, RNA Pol III, etc. There is no exclusive nuclear DNA sensor. Many enzymes known to be present in the cells for their
\end{abstract}

\author{
S. U. Sapre \\ National Institute of Virology, Pune, India \\ P. Nair $(\varangle)$ \\ NMIMS School of Science, Mumbai, India
}


obvious primary functions also additionally function as DNA sensors. The DNAse family of sensors include DNAse II and TREX1, which are ubiquitously present in the cell for their housekeeping functions. The RNAse family of sensor includes one member-RNA Pol III. Additionally, DNA-PK also functions to cater to viral DNA sensing. The endosomal DNA sensors include TLR7 and TLR9, which belong to the Toll-like receptor (TLR) family. The DExD/H-box helicase family include the putative DNA sensors recently discovered including DDX9, DHX36, DDX41 and DDX60. Several other sensors remain to be characterised or are less classified viz. DAI, LRRFIP1, HMGB, ABCF1, MRE11. In general, response to a viral RNA or DNA produces three types of responses, namely, production of antiviral cytokines including Types I and III IFNs, release of pro-inflammatory and inflammatory cytokines and chemotactic factors. This chapter discusses the structure, function and mechanism of action of the viral DNA sensors explored till date.

\section{Keywords}

Viral DNA sensors · Immune responses $\cdot$ Immune activation

\subsection{Introduction}

Defence mechanisms employed by the innate branch of immunity include myriad types of cells and soluble molecules in tissues and circulatory system. Such preexisting deployments constantly thwart the attacks on the organism by the pathogenic microorganisms ubiquitously present throughout the biosphere, thus averting the invasion, establishment and multiplication of such agents. In fact, if microbes do institute a niche, the innate immune responses equip early defence, before the involvement of adaptive branch of the immune system.

The peculiarities of the recognition by players of innate immune system have emerged to contest microbes which have outstanding common features. The innate immunity has evolved to perceive the molecular structures which are present on the surface or inside the microorganism in question, as well as the induced pathogenic microbial products. Such biomolecules which spur the innate immune system are often shared by classes of microbes are called pathogen-associated molecular patterns (PAMPS), or even more appropriately, microbial-associated molecular patterns (MAMPs). Such moieties include nucleic acids (singlestranded RNA/DNA), characteristic feature(s) on protein, carbohydrate and lipid products restricted to microorganisms, or even a combination of the biochemical elements. Such building blocks are often indispensable for the survival of microorganisms. Not only is it capable of recognising the foreign biomolecular structures, but also some, which are derived from self: in aberrant conditions like damaged or dying cells. These substances are known as death- or damage-associated molecular patterns (DAMPs). 
The cell-associated recognition counterpart that assists in perceiving the molecular patterns are called pattern recognition receptors (PRRs). PRRs constitute various types of cell receptors, present in distinct premises of the cell (surface as well as intracellular), as soluble factors in the circulation and other body secretions.
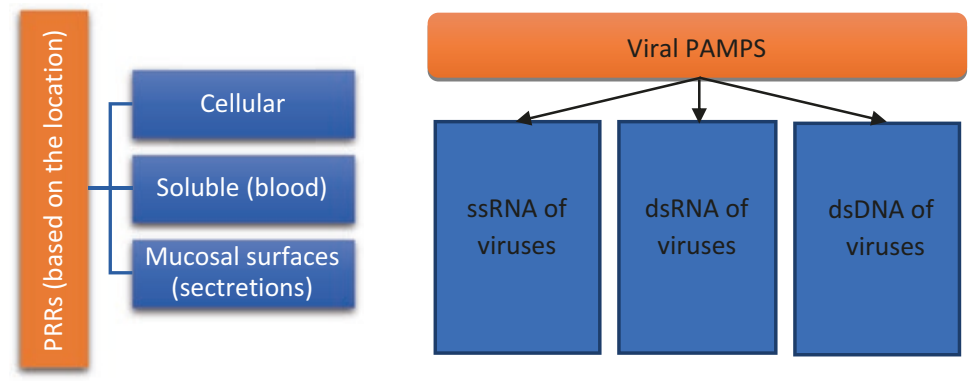

Cell-associated molecules are mostly restricted to the cells of the immune system like phagocytes-Macrophages and Neutrophils; antigen presenting cells (APCs) - Dendritic cells; cells that form the obstacle between the internal milieu and the external environment-epithelial cells; as well as other cells like mast cells and tissue resident cells.

Pathogens like viruses, bacteria, fungi and protozoa can establish themselves within any compartment of the cell viz. cytosol, nucleus, endosomes or on the surface of the cell, tissue, etc. The innate immune system efficiently tackles the microbial invasion in all these compartments by activating the signal transduction pathways downstream of the recognition molecules which ultimately promote the pro-inflammatory and anti-microbe activity.

Broadly though, the pattern recognition receptors can be either cell-associated or soluble.

The cell-associated receptors include:

1. Toll-like receptors (TLRs)

2. NOD-like receptors (NLRs)

3. RIG-I-like receptors (RLRs)

4. Cytosolic DNA sensors (CDSs)

5. C-type lectin-like receptors (CLRs)

6. Scavenger receptors

7. $N$-formyl met-leu-phe receptors

The soluble receptors include:
1. Pentraxins
2. Collectins
3. Ficolins
4. Complement 
The scope of discussion on each of the above PRRs is wide. However, since this chapter specifically deals with the DNA-sensing molecules, further discussion would be restricted to the viral DNA sensors.

\subsection{Sources of Cytosolic DNA}

There are several ways by which DNA can be present in the cell cytoplasm.

These routes include (but are not limited to):

1. Intracellular pathogen infection

2. Impaired ability of clearing exogenous DNA innately metabolised in the endolysosomal compartment

3. An asymmetric management of endogenous DNA products and turnover.

Modes of entry of pathogen DNA in the cytoplasm are depicted below.

The following table summarises the currently known DNA sensors in briefproposed DNA sensor families and the examples:

\begin{tabular}{|c|c|c|c|c|}
\hline PRR & Cell types & $\begin{array}{l}\text { Site of DNA } \\
\text { sensing }\end{array}$ & Response & References \\
\hline \multicolumn{5}{|c|}{ Toll-like receptor (TLR) family } \\
\hline TLR9 & pDCs & Endosomes & Type I IFN & $\begin{array}{l}\text { (Hemmi et al. 2000; } \\
\text { Latz et al. 2004, 2007) }\end{array}$ \\
\hline \multicolumn{5}{|c|}{ PYHIN family } \\
\hline AIM2 & $\begin{array}{l}\text { Macrophages, } \\
\text { DCs }\end{array}$ & Cytoplasm & IL-1 $\beta$, IL-18 & $\begin{array}{l}\text { (Hornung et al. 2009; } \\
\text { Fernandes-Alnemri } \\
\text { et al. 2009; } \\
\text { Burckstummer et al. } \\
\text { 2009; Roberts et al. } \\
\text { 2009) }\end{array}$ \\
\hline IFI16 & $\begin{array}{l}\text { Macrophages, } \\
\text { endothelial cells }\end{array}$ & $\begin{array}{l}\text { Cytoplasm, } \\
\text { nucleus }\end{array}$ & $\begin{array}{l}\text { IFN- } \beta, \text { CXCL10, } \\
\text { IL-6, IL-1 } \beta\end{array}$ & $\begin{array}{l}\text { (Unterholzner et al. } \\
\text { 2010; Horan et al. 2013; } \\
\text { Kerur et al. 2011) }\end{array}$ \\
\hline IFIX & Macrophages & Nucleus & IL-1 $\beta$, IL-18 & (Diner et al. 2015a) \\
\hline MNDA & \multicolumn{4}{|l|}{ Less explored } \\
\hline \multicolumn{5}{|c|}{ STING activator family } \\
\hline cGAS & $\begin{array}{l}\text { L929, THP-1, } \\
\text { HEK293 }\end{array}$ & Cytoplasm & IFN- $\beta$ & (Sun et al. 2013) \\
\hline \multicolumn{5}{|c|}{ DNAse family } \\
\hline DNAse II & Ubiquitous & Lysosomes & DNA degradation & (Okabe et al. 2005) \\
\hline TREX1 & Ubiquitous & $\begin{array}{l}\text { Cytoplasm-ER } \\
\text { associated }\end{array}$ & $\begin{array}{l}\text { Degradation of } \\
\text { DNA elements } \\
\text { derived from } \\
\text { endogenous } \\
\text { retroviruses }\end{array}$ & $\begin{array}{l}\text { (Stetson et al. 2008; } \\
\text { Yang et al. 2007) }\end{array}$ \\
\hline
\end{tabular}




\begin{tabular}{|c|c|c|c|c|}
\hline PRR & Cell types & $\begin{array}{l}\text { Site of DNA } \\
\text { sensing }\end{array}$ & Response & References \\
\hline $\begin{array}{l}\text { RNA Pol } \\
\text { III }\end{array}$ & $\begin{array}{l}\mathrm{EBV}^{+} \mathrm{B} \text { cell, } \\
\text { macrophage, } \\
\text { cell line }\end{array}$ & $\begin{array}{l}\text { Cytoplasm, } \\
\text { nucleus }\end{array}$ & IFN- $\beta$ & $\begin{array}{l}\text { (Ablasser et al. 2009; } \\
\text { Chiu et al. 2009) }\end{array}$ \\
\hline \multicolumn{5}{|c|}{ Protein kinase $(P K)$ family } \\
\hline DNA-PK & 293T, MEFs & Cytoplasm & $\begin{array}{l}\text { IFN- } \lambda 1, \text { IFN- } \beta \text {, } \\
\text { IL-6 }\end{array}$ & $\begin{array}{l}\text { (Zhang et al. 2011a; } \\
\text { Ferguson et al. 2012) }\end{array}$ \\
\hline \multicolumn{5}{|c|}{ DExD/H-box helicase family } \\
\hline DDX9 & pDCs & Cytoplasm & TNF- $\alpha$ & (Kim et al. 2010) \\
\hline DHX36 & pDCs & Cytoplasm & IFN- $\alpha$ & (Kim et al. 2010) \\
\hline DDX41 & DCs & Cytoplasm & IFN- $\alpha, \beta$ & (Zhang et al. 2011b) \\
\hline DDX60 & HeLa cells & Cytoplasm & IFN- $\beta$, CXCL10 & (Miyashita et al. 2011) \\
\hline \multicolumn{5}{|c|}{ Others/less characterised family } \\
\hline DAI & Fibroblasts & Cytoplasm & IFN- $\beta$, necrosis & $\begin{array}{l}\text { (Takaoka et al. 2007; } \\
\text { Upton et al. 2012) }\end{array}$ \\
\hline LRRFIP1 & \multirow[t]{3}{*}{ Less studied } & Cytoplasm & \multirow{2}{*}{$\begin{array}{l}\text { Type I IFN } \\
\text { induction }\end{array}$} & \multirow{2}{*}{$\begin{array}{l}\text { (Sabbah et al. 2009; } \\
\text { Yanai et al. 2009; Yang } \\
\text { et al. 2010) }\end{array}$} \\
\hline HMGB & & Cytoplasm & & \\
\hline ABCF1 & & Cytoplasm & Less known & \\
\hline MRE11 & MEFs, DCs & Cytoplasm & $\begin{array}{l}\text { IFN- } \beta, \text { CXCL10, } \\
\text { IL-6 }\end{array}$ & (Kondo et al. 2013) \\
\hline
\end{tabular}

\subsection{TLR Family}

\subsubsection{Structure}

TLRs belong to the type I integral membrane glycoproteins embedded in the surface membrane or in the endosomal membrane. They possess an extracellular (or intraendosomal) region-characteristic leucine-rich repeats (LRRs) which are surrounded by cysteine-rich motifs which essentially bind ligand(s), a transmembrane region, and an intracellular (or cytosolic) region-known as the Toll/IL-1 receptor (TIR) involved as a part of the cytoplasmic tail. There are about 18-26 copies of LRRs which vary in different TLRs. Each LRR of TLR protein is composed of around 20-25 amino acids and multiple such LRRs make up a typical question mark hook shaped protein scaffold which adapts for ligand binding. Both, the concave as well as convex surfaces, are involved in ligand binding. The N-terminus of a TLR is at its LRR end, whereas the C-terminus is at its TIR end.

\subsubsection{Function}

There are nine different functional TLRs in humans (TLR1-9). The function of TLR-10 is unknown. TLRs always act as dimers. Some of them form heterodimers like TLR-1 and TLR-2, whereas others form homodimers like TLR-3, TLR-4, 
TLR-5, TLR-5, TLR-6, TLR-7, TLR-8, TLR-9 and TLR-10. TLR-1, 2, 4, 5 and 6 are expressed on the surface of the membrane, whereas TLR-3, 7, 8 and 9 are expressed inside the endosomal membrane. TLR-4 utilises accessory proteins MD2, LPS-binding protein (LBP) and CD14.

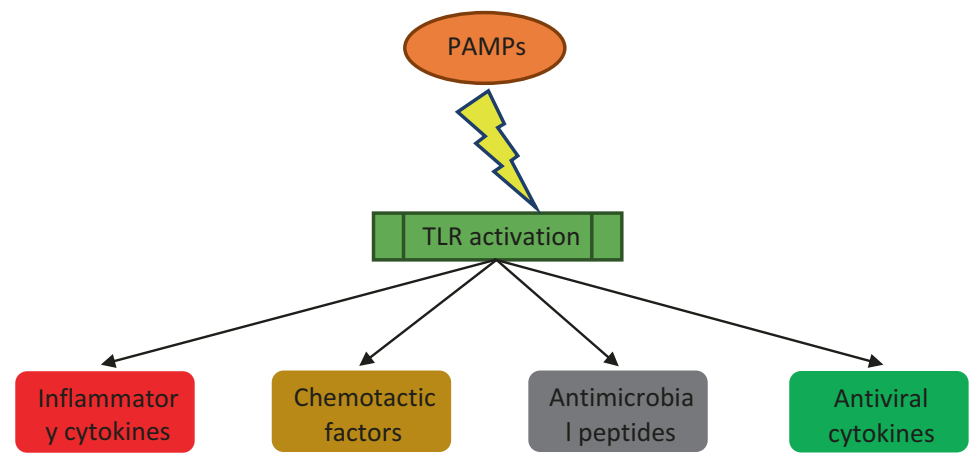

Amongst all, TLR-9 recognises unmethylated $\mathrm{CpG}$ dinucleotides. In the human genome, the DNA methyltransferases heavily methylate cytosine residues. However, in the genome of bacteria and many viruses, $\mathrm{CpG}$ dinucleotides remain unmethylated and thus serve as PAMP. Delivery of TLR-9 (and TLR-3, 7, 8) from the endoplasmic reticulum to the endosome relies on UNC-93B, a protein composed of 12 transmembrane domains. Deficiency of UNC-93B1 due to rare human mutations increases the susceptibility to herpes simplex encephalitis.

\subsubsection{Mechanism of Action}

Ligand binding to the TLR brings about dimerization of the respective TLRs involved. This brings about the cytoplasmic tails to come in proximity. TIR domain containing adaptor proteins are now recruited, which bind the TIR domains in the cytoplasmic tails. Further, this brings about recruitment and activation of distinct protein kinases, which activate the transcription factors. Nuclear factor $\kappa-\mathrm{B}$ (NF$\kappa \mathrm{B})$, activation protein-1 (AP-1), interferon response factor 3 (IRF3) and IRF7 are the major transcription factors which are activated by TLR signalling pathways. NF- $\kappa \mathrm{B}$ and AP-1 are responsible for the expression of genes encoding inflammatory response molecules, including (but not limited to) inflammatory cytokines, endothelial adhesion molecules and chemokines. IRF3 and IRF7 stimulate the production type I interferons (IFNs), which are central to antiviral innate immune responses. Different TLRs use different combination of adaptors and signalling intermediates and thus mediate unique downstream effects. TLR9 uses the MyD88-dependent, TRIF-independent pathway and activates both NF- $\mathrm{KB}$ and IRFs. Hence, they induce both inflammatory and antiviral responses.

Two protein domains of MyD88 allow it to function as an adaptor protein: a TIR domain at its carboxy terminus that associates with the TIR domains of the TLR 
cytoplasmic tails and a death domain at its amino terminus, which associates with the death domains present in other intracellular signalling proteins. It is worthwhile to note that both the domains of MyD88 are essential for signalling. The MyD88 death domain recruits and activates IL-1 receptor associated kinase (IRAK4) and IRAK1, which are both serine-threonine protein kinases. The complex involving IRAK, TIR of cytoplasmic tails and MyD88 executes two functions-executing the enzymes that produce a signalling scaffold, employing the scaffold to recruit other molecules which are then phosphorylated by the IRAKs. The formation of signalling scaffold is a multi-step process: The IRAK complex brings in the enzyme tumour necrosis factor receptor-associated factor 6 (TRAF6), which functions as an E3 ubiquitin ligase in association with TRIKA1 (composed of UBC13, which is an E2 ubiquitin ligase with a cofactor for Uve1A). TRAF6 and UBC13 together have the function of polyubiquitination. This polyubiquitin has linkages between lysine 63 of pervious subunit and $C$ terminus of the next, leading to K63 linkages. The same process can be initiated on vivid proteins, including TRAF6 or the multi-ubiquitin chains can exist independently as free linear chains which can be extended to form polyubiquitin chains, which can bind to other signalling proteins. Further, the scaffold brings in signalling complex that is made up of TAB1, TAB2-ubiquitin binding adaptor molecules, and TAK1-a serine-threonine kinase. IRAK complex phosphorylates TAK1, which propagates signalling by activation of certain MAPKs like c-Jun terminal kinase (JNK) and MAPK14 (p38 MAPK). This brings about downstream activation of AP-1 family of transcription factors which transcribe cytokine genes.

TAK1 additionally phosphorylates and activates the IкB kinase (IKK) complex. IKK $\alpha$, IKK $\beta$ and IKK $\gamma$ constitute the IKK complex (the IKK $\gamma$ is also known as NF-Kb essential modifier or NEMO). NEMO binds to polyubiquitin chains, which leads to IKK complex close to TAK1. TAK1 then activates IKK $\beta$ by its phosphorylation. IKK $\beta$ then phosphorylates inhibitor of $\kappa \mathrm{B}(\mathrm{I \kappa B})$, which is a cytoplasmic protein that natively binds to the transcription factor NF- $\kappa B$. IкB is made up of two

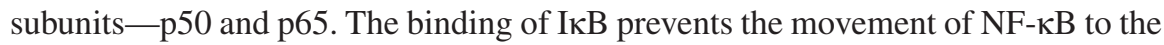
nucleus from cytoplasm. Post phosphorylation of IKK, the IкB is released from the

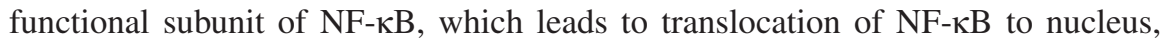
where it leads to transcription of genes for pro-inflammatory cytokines like TNF- $\alpha$, IL-1 $\beta$ and IL-6. It is noteworthy that the effect of TLR activation varies depending on the cell type in which it occurs.

The nucleic acid sensing TLRs, including TLR9 activate IRF family of proteins. Natively present in the cytoplasm, they only get activated upon phosphorylation of serine and threonine residues in their $\mathrm{C}$ terminal. Upon activation, they move to the nucleus to act as transcription factors. Among all the IRFs, IRF3 and IRF7 are particularly important for TLR signalling and expression of antiviral type I IFNs. For TLR9 signalling in plasmacytoid dendritic cells, MyD88 exclusively is used as an adaptor protein. The TIR domain of MyD88 employs IRAK1/IRAK4 complex as described earlier. However, the IRAK complex carries out a different function beyond recruiting TRAFs which generates a signalling scaffold. In these cells, IRAK1 can also interact with IRF7, which is highly expressed by plasmacytoid 
Table 16.1 Containing location of different TLRs, their ligand (Janeway)

\begin{tabular}{|c|c|c|c|c|}
\hline $\begin{array}{l}\text { Toll-like } \\
\text { receptor }\end{array}$ & $\begin{array}{l}\text { Functional } \\
\text { association }\end{array}$ & $\begin{array}{l}\text { Cellular or } \\
\text { subcellular } \\
\text { location }\end{array}$ & Ligand & $\begin{array}{l}\text { Adaptor } \\
\text { proteins }\end{array}$ \\
\hline TLR1 & $\begin{array}{l}\text { TLR1:TLR2 } \\
\text { heterodimer }\end{array}$ & \multirow{2}{*}{$\begin{array}{l}\text { Monocytes, } \\
\text { dendritic cells, } \\
\text { mast cells, } \\
\text { eosinophils, } \\
\text { basophils }\end{array}$} & \multirow{2}{*}{$\begin{array}{l}\text { Lipomannans (mycobacteria), } \\
\text { Lipoproteins (diacyl } \\
\text { lipopeptides; triacyl } \\
\text { lipopeptides); Lipoteichoic } \\
\text { acids (gram-positive bacteria); } \\
\text { cell-wall } \beta \text {-glucans (bacteria } \\
\text { and fungi) }\end{array}$} & \multirow[t]{2}{*}{$\begin{array}{l}\text { MyD88/ } \\
\text { MAL }\end{array}$} \\
\hline TLR2 & $\begin{array}{l}\text { TLR2-TLR6 } \\
\text { heterodimer }\end{array}$ & & & \\
\hline TLR3 & $\begin{array}{l}\text { TLR3-TLR3 } \\
\text { homodimer }\end{array}$ & $\begin{array}{l}\text { Macrophages, } \\
\text { dendritic cells, } \\
\text { intestinal } \\
\text { epithelium }\end{array}$ & $\begin{array}{l}\text { Double-stranded RNA } \\
\text { (viruses), poly I:C }\end{array}$ & TRIF \\
\hline TLR4 & $\begin{array}{l}\text { TLR4-TLR4 } \\
\text { homodimer }\end{array}$ & $\begin{array}{l}\text { Macrophages, } \\
\text { dendritic cells, } \\
\text { mast cells, } \\
\text { eosinophils }\end{array}$ & LPS (gram-negative bacteria) & $\begin{array}{l}\text { MyD88/ } \\
\text { MAL; } \\
\text { TRIF/ } \\
\text { TRAM }\end{array}$ \\
\hline TLR5 & $\begin{array}{l}\text { TLR5-TLR5 } \\
\text { homodimer }\end{array}$ & $\begin{array}{l}\text { Intestinal } \\
\text { epithelium, } \\
\text { macrophages, } \\
\text { dendritic cells }\end{array}$ & Flagellin (bacteria) & MyD88 \\
\hline TLR7 & $\begin{array}{l}\text { TLR7-TLR7 } \\
\text { homodimer }\end{array}$ & $\begin{array}{l}\text { Plasmacytoic } \\
\text { dendritic cells, } \\
\text { macrophages, } \\
\text { eosinophils, B } \\
\text { cells }\end{array}$ & Single-stranded RNA (viruses) & MyD88 \\
\hline TLR8 & $\begin{array}{l}\text { TLR8-TLR8 } \\
\text { homodimer }\end{array}$ & $\begin{array}{l}\text { Macrophages, } \\
\text { neutrophils }\end{array}$ & Single-stranded RNA (viruses) & MyD88 \\
\hline TLR9 & $\begin{array}{l}\text { TLR9-TLR9 } \\
\text { homodimer }\end{array}$ & $\begin{array}{l}\text { Plasmacytoid } \\
\text { dendritic cells, } \\
\text { eosinophils, B } \\
\text { cells, basophils }\end{array}$ & $\begin{array}{l}\text { DNA with unmethylated CpG } \\
\text { (bacteria and herpesviruses) }\end{array}$ & MyD88 \\
\hline TLR10 & $\begin{array}{l}\text { TLR3-TLR3 } \\
\text { homodimer }\end{array}$ & $\begin{array}{l}\text { Plasmacytoid } \\
\text { dendritic cells, } \\
\text { eosinophils, B } \\
\text { cells, basophils }\end{array}$ & Unknown & Unknown \\
\hline
\end{tabular}

dendritic cells. This enables IRAK1 to phosphorylate IRF7 which leads to induction of type I IFNs (Table 16.1).

\subsection{PYHIN Family}

There are 4 PYHIN proteins in humans, and 13 in mice. Two human proteins in this class, namely AIM2 and IFN- $\gamma$ inducible (IFI16) have been predicted based on the studies so far, to be necessary for different DNA-modulated immune responses and perhaps, also function as DNA sensors (Hornung et al. 2009; Roberts et al. 2009; 
Unterholzner et al. 2010). PYHIN family of proteins can also activate the formation of inflammasome.

Inflammasome Inflammasomes is a complex structure which consists of many proteins which form in the cytosol upon stimulation with cytosolic PAMPs and DAMPs, the outcome of which is production of active forms of IL-1 $\beta$ and IL-18. IL1- $\beta$ and IL-18 are actually produced as inactive precursors and their activation is dependent on their proteolytic cleavage by the enzyme caspase-1. These cytokines are then released from the cell, which then promote inflammatory responses. Inflammasomes are made up of oligomers of a sensor, caspase-1, and an adaptor which links the interaction between the rest of the two components. The oligomeric complexes only form upon stimulation with DNA detected by sensors.

\subsubsection{Structure of PYHIN}

The PYHIN family proteins contain an N-terminal pyrin (PY) domain and an $\mathrm{H}$ inversion (HIN) domain

\subsubsection{AIM2}

Absent in melanoma (AIM2) is one such example of a PYHIN family of proteins. The HIN region of AIM2 recognises dsDNA genome and triggers caspase 1 activation. This occurs through the simultaneous interaction of pyrin domain with ASC. Primarily AIM2 is involved in the inflammasome formation (Schattgen and Fitzgerald 2011). Microbial DNA is one such PAMP. It is usually located in the cytosol and is key to responses in vitro to vaccinia virus (Janeway). However, it ubiquitously oligomerises upon stimulation. The downstream aggregates so formed recruit and activate a protease-caspase-1 that leads to the maturation of proinflammatory cytokines IL-1 $\beta$ and IL-18 which ultimately culminates into a programmed cell death, termed 'pyroptosis' (Bergsbaken et al. 2009; Miao et al. 2011).

\subsubsection{IFI16}

Interferon-inducible protein 16 (IFI16) was recently characterised as the first viral DNA sensor to function within the nucleus. It is a member of PYHIN protein family (Diner et al. 2015a; Schattgen and Fitzgerald 2011). IFI16 has two HIN domains. At its $\mathrm{C}$ terminus, it has two HIN200 domains which bind to DNA. At its $\mathrm{N}$-terminal, is a pyrin (PY) domain which mediates homotypic interactions within the molecules as well as cooperative assembly of small subunits of IFI16 (Li et al. 2013; Morrone et al. 2014). This binding is sequence-independent manner (Jin et al. 2012). It primarily functions in the nucleus, where it is located. It recognises viral dsDNA.

The function of IFI16 depends on the type of cell in which it functions. In the immune cells, IFI16 binds to cytosolic viral DNA, engaging sting and induces IFN production (Unterholzner et al. 2010; Horan et al. 2013; Jakobsen et al. 2013). However, in non-immune cells, IFI16 majorly functions in the nucleus by localising 
there (Diner et al. 2015a; Li et al. 2013, 2012; Orzalli et al. 2012). A plausible explanation for this is that the there exists a multi-partite nuclear localisation signal on IFI16 and is necessary for its transit between nucleus and cytoplasm (Li et al. 2012). Especially in case of herpesvirus infections, both IFI16 and STING are required for inducing the expression of IFN and IFN-stimulated genes (Orzalli et al. 2012). The differences in IFI16 DNA-sensing are possibly due to the cell type-dependent process (Diner et al. 2015b). Prompt responses are required in case of immune cells, and thus, DNA-sensing components localised in the cytoplasm makes more sense, whereas, in non-immune cells, the IFI16 might play some housekeeping functions but additionally may respond to the successful viral infections in the nucleus. Additionally, IFI16 also mounts inflammatory and apoptotic responses to foreign DNA through inflammasome - a multiprotein assembly (Kerur et al. 2011; Johnson et al. 2013; Ansari et al. 2013; Singh et al. 2013; Monroe et al. 2014). In reality, the evidence that IFI16 elicits both, type I IFN response as well as inflammation is contradictory, since type I IFNs are known to exhibit anti-inflammatory effect (Theofilopoulos et al. 2005; Billiau 2006; Guarda et al. 2011). Recently, IFI16 was shown to play a direct role in inhibiting the formation of both, AIM2 and NLR family inflammasomes (Veeranki et al. 2011). Hence, it is quite possible that the role of IFI16 in inflammasome responses is cell type dependent and other yet unknown factors do play a role too. Recent evidences suggest that IFI16 and cGAS may function in harmony to execute immune signalling to nuclear foreign DNA (Orzalli et al. 2015). This also suggests that IFI16 is a dominant nuclear DNA sensor, whereas cGAS has auxiliary functions like stabilising the IFI16 to enable or prolong signal efficiency.

\subsubsection{IFIX}

Some of the PYHIN family members, namely, IFIX and MNDA also majorly localise in the nucleus. Yet, their functions were not known in the early phase and were suspected to have some immunological function. IFIX associates with antiviral factors and its expression is inversely associated with the capacity of herpesvirus replication (Diner et al. 2015a) as it binds to the DNA of the virus and remains localised in the nucleus. It binds DNA substrates in a sequence-dependent fashion and leads to type I IFN response (Diner et al. 2015a). IFIX expression, like IFI16, is dependent on the type of cell and tissue, thus making it likely that its function varies from one cell type to other (Ding et al. 2004; Haque et al. 2014).

\subsection{STING Activator Family}

\subsubsection{STING (a.k.a. MITA, ERIS and TMEM173)}

STING is an ER localised transmembrane adaptor protein that is anchored by an amino-terminal tetraspan transmembrane domain. Its carboxy-terminal domain extends into the cytoplasm and interacts to form an inactive form of STING- the STING homodimer. Type I IFN response is crucial for successful defence against 
viral pathogens. Stimulator of IFN genes (STING) is one such pathway vital to the mechanism of dsDNA-induced stimulation of type I IFN responses. If a viral dsDNA happens to exist in the cytosol, post entry and uncoating, it activates the enzyme cGAS (cyclic GMP-AMP synthase) that generates cyclic guanosine monophosphate-adenosine monophosphate (cGAMP), a signalling molecule. cGAS contains a protein motif as a part of the nucelotidyltransferase (NTase) family of enzymes, including adenylate cyclase and distinct DNA polymerases (Janeway). cGAS has an affinity for DNA and readily attaches to the cytosolic DNA. This interaction stimulates the cGAS enzymatic activity that leads to generation of cGAMP from GTP and ATP in the cytoplasm. cGAMP binds to both the subunits of STING dimer and activates STING signalling.

It activates TANK binding kinase 1 (TBK1) through interaction with cGAMP. TBK1 phosphorylates and activates a transcription factor IRF3 which induces expression of type I IFN genes. Besides these, the STING is also known to respond to other cytosolic DNA sensors like DAI and IFI16. Additionally, STING induces autophagy. In the innate immune system, autophagy is a potential mechanism of delivering cytosolic microbes to lysosome where they are acted upon by the proteolytic enzymes.

It is quite interesting to know that STING, MAVS and TRIF, all have similar amino acid sequence motif at their carboxy termini

\subsection{DNAse Family}

\subsubsection{DNAse II}

Cells possess DNAses, which degrade the unwanted DNA in the compartment it is not expected to be present. DNAse II is restricted to lysosomes which digests pathogenic and by-products of dead cells which enter this compartment (Okabe et al. 2005). Originally, this mechanism has evolved for the degradation of the cells undergoing programmed cell death, i.e. apoptosis, which are usually taken up by macrophages. In cells which lack DNAse II activity, DNA may stimulate aberrant responses by entering cytoplasm, consequently stimulating the cytosolic DNA sensors (Okabe et al. 2005).

\subsubsection{TREX1}

Yet another cellular DNAse is three primer repair endonuclease 1(TREX1) that is present in association with the endoplasmic reticulum (ER) in the cytoplasm. Under housekeeping conditions, basal amount of DNA tends to accumulate in the cytosol. TREX1 regularly degrades such DNA in the cytosol. 


\subsection{RNAse Family}

Another putative cytosolic DNA sensor discovered is RNA Polymerase III (PolIII). It uses AT-rich and herpesvirus DNA as a template to produce 5'triphosphate RNAs. RNAs so produced get detected by the cytosolic RNA sensors like RIG-I (Ablasser et al. 2009; Chiu et al. 2009). However, the broad mechanism being the Pol III as a potential DNA senor remains to be completely defined.

\subsection{Protein Kinase (PK) Family}

Some proteins which are usually involved in DNA damage repair also serve as DNA sensors. DNA-PK (DNA-dependent protein kinase which is composed of Ku70, Ku80 and DNA-PKc).

\subsection{DExD/H-Box Helicase Family}

Both, RNA, as well as DNA helicases constitute the DExD/H-box (DDX) protein family which has it characteristic DExD/H-box domain. DDXs are multi-functional and control the gene induction at multiple points that includes signal transduction pathways, gene promoters, mRNA splicing, and translation regulation. Several DNA sensors have been identified in the DDX family (Kim et al. 2010; Zhang et al. 2011b; Yoneyama et al. 2004; Schroder et al. 2008).

\subsubsection{DDX9 and DHX36}

DHX9 and DHX36 are the other two DExD/H-box helicases which bind to CpG DNA and interact with MyD88 (Kim et al. 2010). The inflammatory response and type I interferon response depend partly on DHX9 and DHX36, respectively.

\subsubsection{DDX41}

DEAD box polypeptide 1 (DDX41) is closely related to RIG-I. It appears to signal through the STING. It has been reported that DDX41 interacts with dsDNA, both, in vitro and in vivo. In some cells, it has also been shown to be crucial to the DNAdependent activation of type I IFN production involving STING and TBK1 (Zhang et al. 2011b). In cells where the IFI16 expression is less or restricted, the DDX41 acts as the primary DNA sensor of cytoplasmic DNA which further induced the IFN induction and IFI16 expression, the latter of which, amplifies the innate immune responses (Zhang et al. 2011b). The pattern of DNA sensor expression across different types of cells is vital to define the type of sensor which mediates the DNA primed innate immune responses. Also, recently, DDX41 has also been shown to 
directly bind the cyclic di-nucleotides (CDNs) and thus, indirectly, the IFN response induced was DDX41 dependent (Parvatiyar et al. 2012)

\subsubsection{DDX60}

It is a novice antiviral factor among the pre-existing list of $\mathrm{DExD} / \mathrm{H}$ box helicases and functions in association with RIG-I, MDA5 and LGP2 to induce the type I IFN response (Miyashita et al. 2011).

\subsection{Other/Less Characterised Family}

There are many unknown and known but less characterised candidate DNA sensors. They might play some vital role in other cellular processes, but their role as a DNA sensor is yet to be confirmed. Very less is known regarding their mechanism of recognition and signalling, or their in vivo function.

\subsubsection{DAI}

Another protein is DAI (a.k.a. ZBP1) (Takaoka et al. 2007). The peculiarity of this protein is that the response of DAI as a DNA sensor is decided by the cell type (Unterholzner et al. 2010; Upton et al. 2012, 2010; DeFilippis et al. 2010; Ishii et al. 2008). It interacts with the dsDNA and drives type I IFN response (DeFilippis et al. 2010).

\subsubsection{LRRFIPI}

It senses the DNA present in the cytoplasm and phosphorylates $\beta$-catenin. B-catenin translocates to the nucleus to induce IFN- $\beta$ production.

\subsubsection{HMGB}

Three subtypes of HMGB, viz. HMGB1, HMGB2 and HMGB3 are known to respond to cytosolic DNA. Primarily, ABCF1 binds to the cytosolic DNA. This complex then binds to HMGB2 and IFI16 to stimulate further innate immune response (Yanai et al. 2009; Yang et al. 2010; Lee et al. 2013; Goubau et al. 2013)

\subsubsection{ABCF1}

They function in harmony with the HMGB group of sensors. 


\subsubsection{MRE11}

Meiotic recombination 11 homolog a (MRE11A) has the capability to sense dsDNA in the cytosol and activates STING pathway.

\subsection{Sensing of Viral Components by DNA Sensors}

There are numerous mechanisms through which the DNA sensors in the host cells can detect the viral genomic components and trigger a cascade of downstream reactions. Some of them have been discussed below:

\subsubsection{Herpesviridae}

Till date, the role of DNA sensors has been best studied extensively using herpesviruses, HSV, in particular (Paludan et al. 2011). Quite evidently, currently knownwell, established, as well as prospective DNA sensors have been shown to counteract herpesvirus infections. The very primary DNA sensor was TLR9, followed by the contemporary DNA sensors. To state a few, the HSV-1 infection in human origin primary MDMs (monocyte-derived macrophages) induces the production of proinflammatory cytokines like IL-1 $\beta$, which imitates the response post HSV-1 infection along IFI16 axis (Horan et al. 2013). However, this response is altered when the cell type differs. HSV-1 infection of primary murine dendritic cells (DCs) invokes a type I IFN response with the protein DDX41 involved (Zhang et al. 2011b). IRF3 is known to drive the type I IFN response as well. DAI drives IRF3 activation as well. However, contrastingly, DAI (or ZBP1) is shown to play a central role in inducing necroptosis, post infection with MCMV (Upton et al. 2012).

As discussed earlier, STING is central to all the DNA induced antiviral responses. This coincides with the study which demonstrated that STING deficiency in mice causes increased susceptibility to HSV-1 infection (Ishikawa et al. 2009). While it is not known if the cell-specific response applies to all the cell-lines, the above documented work irrefutably states that the response to herpesvirus infections in primary cells is cell type specific.

\subsubsection{Retroviridae}

HIV is the most widely studied retrovirus for known reasons on its complex pathogenesis, drug resistance and co-evolution with the host. As is known, HIV replication proceeds through and RNA-DNA double-stranded intermediate in the process of its RNA being converted to a dsDNA form. Hence, both, RNA as well as DNA sensors, play a crucial role in the detection of retroviral genome upon target cell entry (Solis et al. 2011; Berg et al. 2012; Doitsh et al. 2010; Yan et al. 2010). A recent study, intended to understand the type I IFN response against HIV proved 
that ssDNA, rather than dsDNA form of HIV, is more potent at inducing the type I IFN response. TREX1 is a $3^{\prime} 5^{\prime}$-exonuclease that degrades the unintegrated cytosolic cDNA, making it unavailable for sensing to the DNA sensors. Eliminating the expression of TREX1 leads to upregulation in type I IFN response and was more so in case of ssRNA intermediate of HIV, rather than dsDNA form. Undoubtedly, thus, cell does employ the intracellular sensors of DNA that culminates in type I IFN response. Although the definite sensors involved remain to be defined to date, they sure function through a STING-TBK1-IRF3 axis.

Other virus families and the respective DNA sensors have been summarised in Table 16.2

\subsubsection{Mechanisms Employed By Viruses to Evade DNA Sensors}

Viral genomes are subject to recognition by DNA sensors only if they happen to expose their characteristic features, leading to the consequent recognition as nonself genomic entity by the host DNA sensing mechanisms. However, myriad viruses evade and subvert the host immune responses so as to render these mechanisms of detecting the viral components ineffective.

One such strategy is to simply obscure their genome and replication intermediates involving potential ligand to the DNA sensors:

Viruses belonging to the Herpesviridae family inhibit DNA sensors like DAI, DHX9 and IFI16 responses.

1. HSV-1 encodes a protein ICP0, an E3 ubiquitin ligase, engages proteasomal degradation of IFI16 and also prevents its nuclear relocalisation. These further limits the activation of IRF3 (Orzalli et al. 2012).

2. HCMV possesses pUL83/pp65, a matrix protein. It inhibits ISG induction. In addition to this, it is known to interact with IFI16 (Cristea et al. 2010).

Table 16.2 Human nuclear replicating DNA viruses and implicated DNA sensors

\begin{tabular}{l|l}
\hline Virus & Implicated DNA sensors \\
\hline $\begin{array}{l}\text { Adenovirus C (types 1,2,5 and } \\
6)\end{array}$ & cGAS, TLR9 \\
\hline Hepatitis B virus & AIM2, cGAS \\
\hline Cytomegalovirus & AIM2, DAI/ZBP1, IFI16, TLR7, TLR9 \\
\hline Epstein-Barr virus & RNA Pol III, IFI16, TLR9 \\
\hline Herpes simplex virus type I & $\begin{array}{l}\text { cGAS, DAI/ZBP1, DDX41, DDX60, DHX9, DHX36, } \\
\text { DNA-PK, RNA Pol III, IFI16, TLR9, IFIX }\end{array}$ \\
\hline Herpes simplex virus type II & DNA-PK, TLR9 \\
\hline $\begin{array}{l}\text { Herpesvirus 8 (Kaposi sarcoma- } \\
\text { associated virus) }\end{array}$ & IFI16 \\
\hline Varicella zoster virus & NLRP3, TLR9 \\
\hline Papillomavirus (>170 types) & TLR9 \\
\hline
\end{tabular}


3. Proteases of viral origin like the NS2B3 protease, coronavirus papain-like proteases subvert STING in a direct manner (Aguirre et al. 2012; Sun et al. 2012; Yu et al. 2012).

Acknowledgements Authors are grateful to NIV Pune and NMIMS Pune for the support extended.

Conflict of Interest The authors declare that they have no competing interests.

\section{References}

Ablasser A et al (2009) RIG-I-dependent sensing of poly(dA:dT) through the induction of an RNA polymerase III-transcribed RNA intermediate. Nat Immunol 10(10):1065-1072

Aguirre S et al (2012) DENV inhibits type I IFN production in infected cells by cleaving human STING. PLoS Pathog 8(10):e1002934

Ansari MA et al (2013) Constitutive interferon-inducible protein 16-inflammasome activation during Epstein-Barr virus latency I, II, and III in B and epithelial cells. J Virol 87(15):8606-8623

Berg RK et al (2012) Genomic HIV RNA induces innate immune responses through RIG-Idependent sensing of secondary-structured RNA. PLoS One 7(1):e29291

Bergsbaken T, Fink SL, Cookson BT (2009) Pyroptosis: host cell death and inflammation. Nat Rev Microbiol 7(2):99-109

Billiau A (2006) Anti-inflammatory properties of Type I interferons. Antivir Res 71(2-3):108-116

Burckstummer T et al (2009) An orthogonal proteomic-genomic screen identifies AIM2 as a cytoplasmic DNA sensor for the inflammasome. Nat Immunol 10(3):266-272

Chiu YH, Macmillan JB, Chen ZJ (2009) RNA polymerase III detects cytosolic DNA and induces type I interferons through the RIG-I pathway. Cell 138(3):576-591

Cristea IM et al (2010) Human cytomegalovirus pUL83 stimulates activity of the viral immediateearly promoter through its interaction with the cellular IFI16 protein. J Virol 84(15):7803-7814

DeFilippis VR et al (2010) Human cytomegalovirus induces the interferon response via the DNA sensor ZBP1. J Virol 84(1):585-598

Diner BA et al (2015a) The functional interactome of PYHIN immune regulators reveals IFIX is a sensor of viral DNA. Mol Syst Biol 11(1):787

Diner BA, Lum KK, Cristea IM (2015b) The emerging role of nuclear viral DNA sensors. J Biol Chem 290(44):26412-26421

Ding Y et al (2004) Antitumor activity of IFIX, a novel interferon-inducible HIN-200 gene, in breast cancer. Oncogene 23(26):4556-4566

Doitsh $\mathrm{G}$ et al (2010) Abortive HIV infection mediates CD4 T cell depletion and inflammation in human lymphoid tissue. Cell 143(5):789-801

Ferguson BJ et al (2012) DNA-PK is a DNA sensor for IRF-3-dependent innate immunity. elife 1:e00047

Fernandes-Alnemri T et al (2009) AIM2 activates the inflammasome and cell death in response to cytoplasmic DNA. Nature 458(7237):509-513

Goubau D, Deddouche S, Reis e Sousa C (2013) Cytosolic sensing of viruses. Immunity 38(5): $855-869$

Guarda G et al (2011) Type I interferon inhibits interleukin-1 production and inflammasome activation. Immunity $34(2): 213-223$ 
Haque A et al (2014) Mouse pyrin and HIN domain family member 1 (pyhin1) protein positively regulates LPS-induced IFN-beta and NO production in macrophages. Innate Immun 20(1):40-48

Hemmi H et al (2000) A toll-like receptor recognizes bacterial DNA. Nature 408(6813):740-745

Horan KA et al (2013) Proteasomal degradation of herpes simplex virus capsids in macrophages releases DNA to the cytosol for recognition by DNA sensors. J Immunol 190(5):2311-2319

Hornung $\mathrm{V}$ et al (2009) AIM2 recognizes cytosolic dsDNA and forms a caspase-1-activating inflammasome with ASC. Nature 458(7237):514-518

Ishii KJ et al (2008) TANK-binding kinase-1 delineates innate and adaptive immune responses to DNA vaccines. Nature 451(7179):725-729

Ishikawa H, Ma Z, Barber GN (2009) STING regulates intracellular DNA-mediated, type I interferon-dependent innate immunity. Nature 461(7265):788-792

Jakobsen MR et al (2013) IFI16 senses DNA forms of the lentiviral replication cycle and controls HIV-1 replication. Proc Natl Acad Sci U S A 110(48):E4571-E4580

Jin $T$ et al (2012) Structures of the HIN domain: DNA complexes reveal ligand binding and activation mechanisms of the AIM2 inflammasome and IFI16 receptor. Immunity 36(4):561-571

Johnson KE, Chikoti L, Chandran B (2013) Herpes simplex virus 1 infection induces activation and subsequent inhibition of the IFI16 and NLRP3 inflammasomes. J Virol 87(9):5005-5018

Kerur N et al (2011) IFI16 acts as a nuclear pathogen sensor to induce the inflammasome in response to Kaposi Sarcoma-associated herpesvirus infection. Cell Host Microbe 9(5):363-375

Kim T et al (2010) Aspartate-glutamate-alanine-histidine box motif (DEAH)/RNA helicase A helicases sense microbial DNA in human plasmacytoid dendritic cells. Proc Natl Acad Sci U S A 107(34):15181-15186

Kondo T et al (2013) DNA damage sensor MRE11 recognizes cytosolic double-stranded DNA and induces type I interferon by regulating STING trafficking. Proc Natl Acad Sci U S A 110(8):2969-2974

Latz E et al (2004) TLR9 signals after translocating from the ER to CpG DNA in the lysosome. Nat Immunol 5(2):190-198

Latz E et al (2007) Ligand-induced conformational changes allosterically activate Toll-like receptor 9. Nat Immunol 8(7):772-779

Lee MN et al (2013) Identification of regulators of the innate immune response to cytosolic DNA and retroviral infection by an integrative approach. Nat Immunol 14(2):179-185

Li T et al (2012) Acetylation modulates cellular distribution and DNA sensing ability of interferoninducible protein IFI16. Proc Natl Acad Sci U S A 109(26):10558-10563

Li T, Chen J, Cristea IM (2013) Human cytomegalovirus tegument protein pUL83 inhibits IFI16mediated DNA sensing for immune evasion. Cell Host Microbe 14(5):591-599

Miao EA, Rajan JV, Aderem A (2011) Caspase-1-induced pyroptotic cell death. Immunol Rev 243(1):206-214

Miyashita M et al (2011) DDX60, a DEXD/H box helicase, is a novel antiviral factor promoting RIG-I-like receptor-mediated signaling. Mol Cell Biol 31(18):3802-3819

Monroe KM et al (2014) IFI16 DNA sensor is required for death of lymphoid CD4 T cells abortively infected with HIV. Science 343(6169):428-432

Morrone SR et al (2014) Cooperative assembly of IFI16 filaments on dsDNA provides insights into host defense strategy. Proc Natl Acad Sci U S A 111(1):E62-E71

Okabe $\mathrm{Y}$ et al (2005) Toll-like receptor-independent gene induction program activated by mammalian DNA escaped from apoptotic DNA degradation. J Exp Med 202(10):1333-1339

Orzalli MH, DeLuca NA, Knipe DM (2012) Nuclear IFI16 induction of IRF-3 signaling during herpesviral infection and degradation of IFI16 by the viral ICP0 protein. Proc Natl Acad Sci U S A 109(44):E3008-E3017

Orzalli MH et al (2015) cGAS-mediated stabilization of IFI16 promotes innate signaling during herpes simplex virus infection. Proc Natl Acad Sci U S A 112(14):E1773-E1781

Paludan SR et al (2011) Recognition of herpesviruses by the innate immune system. Nat Rev Immunol 11(2):143-154 
Parvatiyar K et al (2012) The helicase DDX41 recognizes the bacterial secondary messengers cyclic di-GMP and cyclic di-AMP to activate a type I interferon immune response. Nat Immunol 13(12):1155-1161

Roberts TL et al (2009) HIN-200 proteins regulate caspase activation in response to foreign cytoplasmic DNA. Science 323(5917):1057-1060

Sabbah A et al (2009) Activation of innate immune antiviral responses by Nod2. Nat Immunol 10(10):1073-1080

Schattgen SA, Fitzgerald KA (2011) The PYHIN protein family as mediators of host defenses. Immunol Rev 243(1):109-118

Schroder M, Baran M, Bowie AG (2008) Viral targeting of DEAD box protein 3 reveals its role in TBK1/IKKepsilon-mediated IRF activation. EMBO J 27(15):2147-2157

Singh VV et al (2013) Kaposi's sarcoma-associated herpesvirus latency in endothelial and B cells activates gamma interferon-inducible protein 16-mediated inflammasomes. J Virol 87(8): $4417-4431$

Solis M et al (2011) RIG-I-mediated antiviral signaling is inhibited in HIV-1 infection by a protease-mediated sequestration of RIG-I. J Virol 85(3):1224-1236

Stetson DB et al (2008) Trex 1 prevents cell-intrinsic initiation of autoimmunity. Cell 134(4):587-598

Sun L et al (2012) Coronavirus papain-like proteases negatively regulate antiviral innate immune response through disruption of STING-mediated signaling. PLoS One 7(2):e30802

Sun L et al (2013) Cyclic GMP-AMP synthase is a cytosolic DNA sensor that activates the type I interferon pathway. Science 339(6121):786-791

Takaoka A et al (2007) DAI (DLM-1/ZBP1) is a cytosolic DNA sensor and an activator of innate immune response. Nature 448(7152):501-505

Theofilopoulos AN et al (2005) Type I interferons (alpha/beta) in immunity and autoimmunity. Annu Rev Immunol 23:307-336

Unterholzner L et al (2010) IFI16 is an innate immune sensor for intracellular DNA. Nat Immunol 11(11):997-1004

Upton JW, Kaiser WJ, Mocarski ES (2010) Virus inhibition of RIP3-dependent necrosis. Cell Host Microbe 7(4):302-313

Upton JW, Kaiser WJ, Mocarski ES (2012) DAI/ZBP1/DLM-1 complexes with RIP3 to mediate virus-induced programmed necrosis that is targeted by murine cytomegalovirus vIRA. Cell Host Microbe 11(3):290-297

Veeranki S et al (2011) IFI16 protein mediates the anti-inflammatory actions of the type-I interferons through suppression of activation of caspase- 1 by inflammasomes. PLoS One 6(10):e27040

Yan $\mathrm{N}$ et al (2010) The cytosolic exonuclease TREX1 inhibits the innate immune response to human immunodeficiency virus type 1. Nat Immunol 11(11):1005-1013

Yanai $\mathrm{H}$ et al (2009) HMGB proteins function as universal sentinels for nucleic-acid-mediated innate immune responses. Nature 462(7269):99-103

Yang YG, Lindahl T, Barnes DE (2007) Trex1 exonuclease degrades ssDNA to prevent chronic checkpoint activation and autoimmune disease. Cell 131(5):873-886

Yang P et al (2010) The cytosolic nucleic acid sensor LRRFIP1 mediates the production of type I interferon via a beta-catenin-dependent pathway. Nat Immunol 11(6):487-494

Yoneyama $\mathrm{M}$ et al (2004) The RNA helicase RIG-I has an essential function in double-stranded RNA-induced innate antiviral responses. Nat Immunol 5(7):730-737

Yu CY et al (2012) Dengue virus targets the adaptor protein MITA to subvert host innate immunity. PLoS Pathog 8(6):e1002780

Zhang X et al (2011a) Cutting edge: Ku70 is a novel cytosolic DNA sensor that induces type III rather than type I IFN. J Immunol 186(8):4541-4545

Zhang Z et al (2011b) The helicase DDX41 senses intracellular DNA mediated by the adaptor STING in dendritic cells. Nat Immunol 12(10):959-965 